\title{
Impact of sleep problems on daytime function in school life: a cross-sectional study involving Japanese university students
}

Momoko Kayaba ${ }^{1,2^{*}}$, Toshiko Matsushita ${ }^{3}$, Minori Enomoto ${ }^{4}$, Chieko Kanai ${ }^{5}$, Noriko Katayama ${ }^{6}$, Yuichi Inoue ${ }^{1,2}$ and Taeko Sasai-Sakuma ${ }^{1,2,7}$

\begin{abstract}
Background: The aims of this study were 1) to clarify the prevalence of sleep problems (insomnia, insufficient sleep, and delayed sleep-wake phase) among Japanese university students; 2) to examine sociodemographic characteristics, lifestyle, and sleep-related symptoms in each sleep problem; and 3) to evaluate the association between the above-mentioned sleep problems and daytime dysfunction in school life.
\end{abstract}

Methods: Self-report questionnaire surveys were conducted at eight universities in Japan, and we received 1034 valid answers (78\% female). The questionnaire consisted of socio-demographic characteristics, information on lifestyle, sleep pattern, sleep-related symptoms, and daytime dysfunction in school life. Groups with insomnia, behaviorally induced insufficient sleep syndrome (BIISS), delayed sleep-wake phase (DSWP), and BIISS + DSWP were defined. To identify the association between sleep problems and daytime dysfunction in school life, the generalized linear mixed effect model was conducted.

Results: Sleep duration on weekdays was $5.9 \pm 1.2 \mathrm{~h}$, and $38.2 \%$ of the students had a sleep duration $<6.0 \mathrm{~h}$. About $16 \%$ of the students were categorized as evening-type individuals. More than half of the students $(56.1 \%)$ had excessive daytime sleepiness. Insomnia was associated with tardiness (aOR: 0.8, 95\%Cl: 0.7-0.9) and falling asleep during class (aOR: 1.6: 95\%Cl: 1.4-2.0). BIISS was associated with tardiness (aOR: 1.5, 95\%Cl: 1.1-2.2) and interference with academic achievement (aOR: 1.9, 95\%Cl: 1.3-2.6). DSWP and BIISS + DSWP were associated with absence (aOR: 3.4, 95\%Cl: 2.2-5.1 / aOR: 4.2, 95\%Cl: 3.2-5.6), tardiness (aOR: 2.7, 95\%Cl: 1.8-4.1 / aOR: 2.2, 95\%Cl: 1.6-2.8), falling asleep during class (aOR: 2.6, 95\%Cl: 1.4-4.8 / aOR: 7.6, 95\%Cl: 3.3-17.2), and interference with academic achievement (aOR: 2.6, 95\%Cl: 1.7-3.9 / aOR: 2.1, 95\%Cl: 1.6-2.8).

(Continued on next page)

\footnotetext{
* Correspondence: momoko-k@tokyo-med.ac.jp

'Department of Somnology, Tokyo Medical University, 6-7-1 Nishishinjuku, Shinjuku-ku, Tokyo 160-0023, Japan

2Japan Somnology Center, Institute of Neuropsychiatry, 5-10-10, Yoyogi,

Shibuya-ku, Tokyo 151-0053, Japan

Full list of author information is available at the end of the article
}

(c) The Author(s). 2020 Open Access This article is licensed under a Creative Commons Attribution 4.0 International License, which permits use, sharing, adaptation, distribution and reproduction in any medium or format, as long as you give appropriate credit to the original author(s) and the source, provide a link to the Creative Commons licence, and indicate if changes were made. The images or other third party material in this article are included in the article's Creative Commons licence, unless indicated otherwise in a credit line to the material. If material is not included in the article's Creative Commons licence and your intended use is not permitted by statutory regulation or exceeds the permitted use, you will need to obtain permission directly from the copyright holder. To view a copy of this licence, visit http://creativecommons.org/licenses/by/4.0/. The Creative Commons Public Domain Dedication waiver (http://creativecommons.org/publicdomain/zero/1.0/) applies to the data made available in this article, unless otherwise stated in a credit line to the data. 
(Continued from previous page)

Conclusions: Students with DSWP and BIISS + DSWP were significantly associated with daytime dysfunction in school life, i.e. absence, tardiness, falling asleep during class and interference with academic achievement. Students displaying BIISS + DSWP were considered to have a relatively more serious condition compared with those with only insomnia, DSWP, or BIISS. It is therefore of utmost importance that university students aim to prevent DSWP and BIISS which were associated with daytime function in school life.

Keywords: Insomnia, Behaviorally induced insufficient sleep syndrome, Delayed sleep-wake phase, Attendance, Tardiness, Daytime dysfunction

\section{Background}

Sleep pattern and sleep problems vary depending on socio-demographic factors. Steptoe et al. reported that the average sleep duration for university students ranges from six to more than 8 hours in different countries, and no less than $21 \%$ of them have a short sleep duration $(6 \%,<6 \mathrm{~h} ; 15 \%, 6-7 \mathrm{~h})$ [1]. The study also revealed that the average sleep duration among university students in Asian countries including Japan (6.1 h), Taiwan $(6.6 \mathrm{~h})$, and Korea $(6.8 \mathrm{~h})$ were markedly shorter than those in other countries (over $7 \mathrm{~h}$ ). In addition, the young population are likely to show the latest chronotype among all generations [2]; delayed endogenous circadian clock in the young population, school work, extracurricular activities, club activities, or part-time jobs may delay their bed time. Moreover, early awakening to adapt to their social schedule (e.g., for attending classes early in the morning) consequently brings about insufficient sleep especially in evening-type students. Numerous studies have reported that either insufficient sleep or later chronotype is associated with deterioration of physical health, mental health [3-5] and health-related quality of life [6, 7] as well as worse academic performance [8-12] in the young population.

It has been reported that as high as $33-59 \%$ of university students have poor sleep quality, which is associated with their worsened health status and academic performance [5, 13-19]. In these previous studies, sleep quality was defined as "poor" or "good" using the Pittsburg Sleep Quality Index (PSQI), a widely used scale evaluating the following seven components: subjective sleep quality, sleep latency, sleep duration, habitual sleep efficiency, sleep disturbances, use of sleep medication, and daytime dysfunction [20]. However, the PSQI score cannot determine what kind of sleep problems affect academic performance.

To improve students' physical health, mental health, and academic performance, the American Academy of Pediatrics recommended a delayed school start time for adolescents [21]. Actually, several studies involving trials with delayed school start time recorded an increase in the sleep duration of students on weekdays, and consequently, improved mental health and daytime alertness in adolescents [22-24]. In university students, personal factors such as private activities rather than social schedule are likely to affect sleep duration because they do not have to keep a strict sleep-wake rhythm like junior / senior high school students who have to go to school on a regular schedule. Therefore, the characteristics of both university class schedules (e.g., school hours or class start time) and students' lifestyle (e.g., commute time or living alone or with family) should be considered. Sleep problems, including insufficient sleep, insomnia, and sleep disorders, were categorized as "poor sleep" in previous studies. However, related factors and association with daytime dysfunction might differ among students with different sleep problems. Furthermore, few studies have evaluated daytime dysfunction in school life, such as absence, tardiness, and falling asleep during class, although test scores (e.g., grade point average) have been used to evaluate academic performance $[8,9,12]$.

The aims of this study were 1) to clarify the prevalence of sleep problems (insomnia, insufficient sleep, and delayed sleep-wake phase) among Japanese university students; 2) to examine sociodemographic characteristics, lifestyle, and sleep-related symptoms in each sleep problem; and 3) to evaluate the association between the above-mentioned sleep problems and daytime dysfunction in school life.

\section{Method \\ Participants and data collection}

This cross-sectional study was conducted at eight universities in Japan between May 2018 and March 2019. Research collaborators from the fields of sleep science and psychiatric nursing were invited to participate in the study. Universities whose research collaborators both explained the survey and obtained ethical approval participated in this study. Research collaborators from the following university departments participated in the study: the faculty of nursing ( 4 universities), medical technology (2 universities), child development and education ( 1 women's university), and science (1 university). Except for a university in the Tohoku region $(n=57)$, all the universities were located in the Kanto region (i.e. Tokyo, Kanagawa, Chiba). Self-reported questionnaires 
were distributed to undergraduate students during classes and were collected by means of a collection box or envelope so that answerers could not be identified, in accordance with the administrative regulation of the ethical approval committee in each university. We received 1069 questionnaires from eligible students (response rate, $78.3 \%$ ) with 1034 valid answers, of which 225 of the respondents were male (21.8\%) and 809 were female (78.2\%). Twenty-two respondents were excluded from subsequent analyses according to exclusion criteria; no information on age, sex, or sleep pattern. Furthermore, students older than 22 years $(n=13)$ were excluded to limit age-dependent sleep variations within the "normal" age range of university students, i.e. $18-22$ years.

\section{Measures}

The questionnaire was written in Japanese and consisted of the following items.

\section{Characteristics of the participants}

For sociodemographic characteristics and lifestyle, students were required to answer questions on age, sex, grade, starting and closing time of class, whether they were living alone or not, commute time, club activities and/or part-time job, exercise habits per week ( $\geq 4$ days /2-3 days/ $\leq 1$ days/ none), alcohol consumption, smoking, self-rated health status, feeling stress, and use of sleep medication. Frequency of exercise habit was converted into a binary outcome (0: none, $1: \geq 4$ days $/ 2-3$ days/ $\leq 1$ days) for analysis.

\section{Sleep variables and definition of sleep problems}

Data on sleep pattern included information on sleep duration, bedtime, awakening time on weekdays and on weekends, and extension of sleep duration on weekends. In addition to nocturnal sleep, we enquired about daytime nap (length and dreaming). The Japanese version of Epworth Sleepiness Scale (ESS) $[25,26]$ was used to assess the level of daytime sleepiness. The total sum score ranges from 0 to 24 , and $\geq 11$ is regarded as having excessive daytime sleepiness. Students indicated when their daytime sleepiness started as well. To assess chronotype, the Japanese version of Morningness-Eveningness Questionnaire (MEQ) [27, 28] was used. This questionnaire consists of 19 items, and a total score below 42 is defined as evening-type, 42-58 as neutral-type, and above 58 as morning-type. Sleep quality was assessed with the Japanese version of Athens Insomnia Scale (AIS) [29, 30], which indicates possible insomnia when one has a score above five out of the total score. In order to assess sleep-related symptoms, the self-report questionnaire included questions on whether the students had any insomnia symptoms (difficulty initiating sleep, difficulty maintaining sleep, and/or early morning awakening), difficulty awakening, REM sleep-related symptoms (hypnagogic hallucination and/or sleep paralysis), NREM parasomnias (night terrors, defective awakening, and/or sleep walking), and REM parasomnias (nightmare and/or acting out their dreams).

In order to evaluate the association between sleep problems and daytime dysfunction in school life, we defined groups with insomnia, behaviorally induced insufficient sleep syndrome (BIISS), delayed sleep-wake phase (DSWP), and BIISS + DSWP as follows: Students who had an AIS score $\geq 6$ and one or more of "Difficulty initiating sleep," "Difficulty maintaining sleep," and "Early morning awakening" were categorized as students with "Insomnia". The groups with BIISS, DSWP, and BIISS + DSWP were categorized as shown in Fig. 1. Students whose sleep duration on weekdays was $<6 \mathrm{~h}$, extension of sleep duration on weekends was $\geq 2 \mathrm{~h}$, bedtime on weekdays was before $1 \mathrm{am}$, with MEQ score $\geq 42$, and ESS score $\geq 11$ were classified as having "BIISS", the BIISS without DSWP group. Students whose sleep duration on weekdays was $\geq 6 \mathrm{~h}$, extension of sleep duration on weekends was $<2 \mathrm{~h}$, and bedtime on weekdays and weekends was after 1 am with MEQ score $<42$ were classified as having "DSWP", the DSWP without BIISS group. Students whose sleep duration on weekdays was $<6 \mathrm{~h}$, extension of sleep duration on weekends was $\geq 2 \mathrm{~h}$, bedtime on weekdays and weekends was after $1 \mathrm{am}$, with MEQ score $<42$, and ESS score $\geq 11$ were classified into the "BIISS + DSWP" group.

\section{Daytime dysfunction in school life}

The questionnaire included questions on frequency of absence, tardiness, and falling asleep during class (often/ sometimes/none) and interference with academic achievement (yes/no). Frequency was converted into a binary outcome (0: none, 1: often/sometimes) for calculating odds ratio.

\section{Statistical analyses}

Representative values were shown as mean \pm standard deviation (SD). Mann-Whitney U tests and Chi-square tests followed by residual analyses were performed for continuous variables and categorical variables, respectively. To identify the association between sleep problems and daytime dysfunction in school life, the generalized linear mixed effect model was conducted. In the model, explanatory variables; sociodemographic characteristics, and lifestyle variables (sex, commute time, etc.) and sleep problems (presence/absence of insomnia, BIISS, DSWP, and BIISS + DSWP) were set as fixed effects, whereas university and grade were set as random effects. In the present study, insufficient sleep, delayed sleep phase, or combination of these two sleep problems were used as defined variables instead of original sleep 


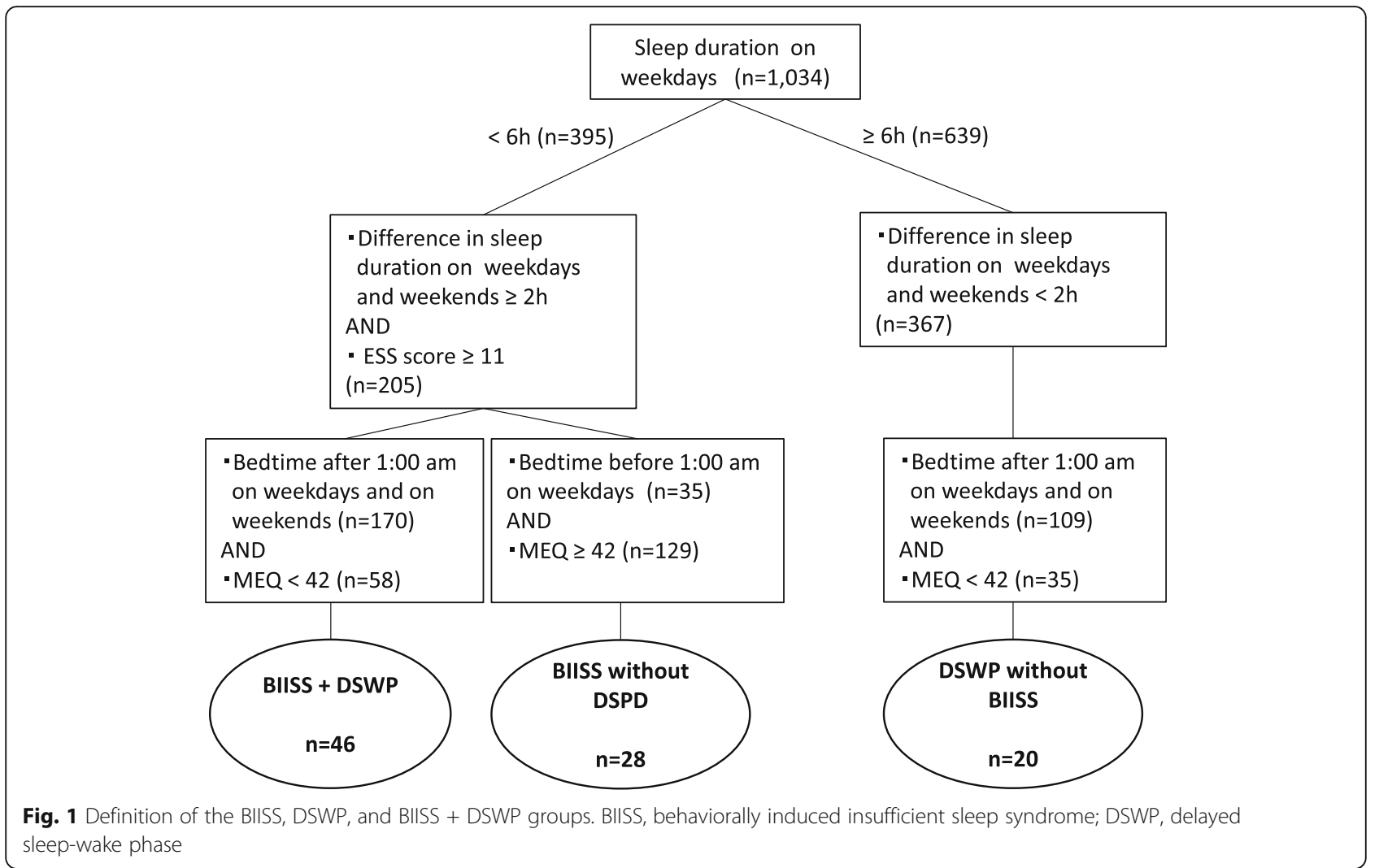

parameters (e.g., sleep duration, MEQ score) in order to distinguish the impact of each sleep problem clearly. In the analysis of the generalized linear mixed effect model, the degree of association was represented as adjusted odds ratio $(\mathrm{aOR})$ and $95 \%$ confidential interval $(95 \% \mathrm{CI})$. These analyses involved multiple imputation by chained equations with a five-imputation dataset using logistic regression and a multinomial logit model for the categorical variables, as well as predictive mean matching for the numeric variables [31]. The significance level was defined as $p<0.05$. Generalized linear mixed effect model analysis and multiple imputation by chained equations were performed using $\mathrm{R}$ statistical software version 3.5.1 ( $\mathrm{R}$ Core Team, Vienna, Austria), "Ime4" package [32] and "mice" package [33], and other analysis were performed by IBM SPSS Statistics 25 (IBM Corporation, Armonk, USA).

This manuscript was written in accordance with the STROBE statement for cross-sectional studies [34]. Ethical approval for this survey was granted by the Ethical Committee of the Tokyo Medical University and Institute of Neuropsychiatry.

\section{Results}

\section{Characteristics of students}

Characteristics of the study participants and their lifestyle data are shown in Table 1. Among the study participants there were more female (78.2\%) than male students $(21.8 \%)$. This study found that $21.1 \%$ of students lived alone. The results also found a mean commute time of $59.6 \pm 33.9 \mathrm{~min}$. Mean school hours were $6.9 \pm 1.8 \mathrm{~h}(9: 19-16: 15)$. The percentage of the students who had club activities, part-time jobs, and exercise habits were $38.9,66.3$, and $48.3 \%$, respectively. The average frequency per week was $1.7 \pm 1.1$ times for club activities and $2.6 \pm 1.1$ times for part-time jobs; $34.1 \%$ of the students with a part-time job worked after $11 \mathrm{pm}$. The percentage of the students who have alcohol consumption and smoking habits were 48 and $5.2 \%$, respectively. The students who reported poor health and feeling stress accounted for 27.0 and $45.0 \%$ of the study population, respectively.

\section{Prevalence of sleep problems and sleep-wake pattern in Japanese university students}

Habitual sleep schedules, chronotype, and presence of insomnia are summarized in Table 2. Sleep duration on weekdays was $5.9 \pm 1.2 \mathrm{~h}$, and $38.2 \%$ of the students had a sleep duration $<6.0 \mathrm{~h}$. Extension of sleep duration on weekends for the students was $2.1 \pm 1.7 \mathrm{~h}$, and $55.8 \%$ of them had an extension of $\geq 2.0 \mathrm{~h}$. According to the MEQ score, $16.2 \%$ of the students were categorized as evening-type individuals. The ESS score was $11.4 \pm 4.6$, and $56.1 \%$ of the students had excessive daytime 
Table 1 Demographic characteristics and lifestyle data of the participants

\begin{tabular}{ll}
\hline Age $(\mathrm{y})$ & $n=1034$ \\
Sex & $19.7 \pm 1.2$ \\
$\quad$ Male $\mathrm{n}(\%)$ & $225(21.8)$ \\
Female $\mathrm{n}(\%)$ & $809(78.2)$
\end{tabular}

Grade

Freshman n (\%)

369 (35.7)

Sophomore $\mathrm{n}(\%)$

$236(22.8)$

Junior n (\%)

Senior n (\%)

N/A n (\%)

Living alone

Yes $n(\%)$

No $n(\%)$

N/A n (\%)

Commute time (min)

School hours (h)

Class start time (h:m)

Class closing time (h:m)

Club activities

Yes $\mathrm{n}(\%)$

No n (\%)

N/A n (\%)

Part-time job

Yes $\mathrm{n}(\%)$

No $n(\%)$

N/A n (\%)

Exercise habit

Yes $\mathrm{n}(\%)$

No $n(\%)$

N/A $n(\%)$

Alcohol consumption

Yes n (\%)

No $n(\%)$

N/A n (\%)

Smoking

Yes $\mathrm{n}(\%)$

No $n(\%)$

N/A n (\%)

Self-rated health status

Good n (\%)

Poor n (\%)

N/A n (\%)

$6.9 \pm 1.8$

$9: 19 \pm 0: 46$

$16: 15 \pm 1: 37$

$402(38.9)$

$613(59.3)$

$19(1.8)$

$686(66.3)$

$333(32.2)$

$15(1.5)$

$499(48.3)$

$519(50.2)$

$16(1.5)$

$437(42.3)$

$584(56.5)$

$13(1.3)$

$54(5.2)$

$967(93.5)$

$13(1.3)$

$740(71.6)$

$279(27.0)$

$15(1.5)$
Table 1 Demographic characteristics and lifestyle data of the participants (Continued)

\begin{tabular}{ll}
\hline & $n=1034$ \\
\hline Stress & $554(53.6)$ \\
No $n(\%)$ & $465(45.0)$ \\
Yes $n(\%)$ & $15(1.5)$ \\
N/A n (\%) & \\
\hline $\begin{array}{l}\text { Values are expressed as mean } \pm \text { standard deviation for continuous variables } \\
\text { N/A Unanswered }\end{array}$
\end{tabular}

sleepiness. Age at the self-reported onset of daytime sleepiness was $14.6 \pm 3.1$ years. The students who had AIS score $\geq 6$ accounted for $52.6 \%$ of the total population, and $24.9 \%$ of the students met the criteria for insomnia. The prevalence of BIISS and DSWP were 6.6 and $5.8 \%$, respectively (Fig. 2). In accordance with definitions (See 2.2.3), 28, 20 and 40 students were categorized into the groups of BIISS, DSWP and BIISS+DSWP, respectively. Eight students (0.8\%) reported sleeping medication taking. The prevalence of sleep-related symptoms is also shown in Fig. 2.

\section{Sociodemographic characteristics, lifestyle and sleep-} related symptoms in each sleep problem

Sociodemographic characteristics, lifestyle and sleeprelated symptoms in each group of sleep problems were shown in Table 3. In the Insomnia group, age was higher, the students who had club activity were less prevalent, percentages of the students whose perceived health was poor and who had stress were higher than in the group without insomnia. Regarding nap habit, the percentages of the students who take a nap for over an hour and those who often dream during their nap were significantly higher than in the groups without insomnia. Regarding sleep-related symptoms, the percentages of the students with possible symptoms of not only insomnia symptoms (difficulty initiating sleep, difficulty maintaining sleep and early morning awakening) but also hypnagogic hallucination, sleep paralysis, REM parasomnia, and NREM parasomnia in the insomnia group were higher than in those without insomnia. In the BIISS group, all students were female and did not live alone. Commute time was longer, class start time was earlier, and the percentages of the students who had club activity and exercise habit were lower in the BIISS group than in the group without BIISS. In the DSWP group, the students who lived alone and had smoking habit were more prevalent, commute time and school hours were shorter, class start time was later than in the group without DSWP. Regarding sleep-related symptoms, difficulty awakening and NREM parasomnia were more frequently observed in the DSWP group than in the group without DSWP. In the BIISS + DSWP group, the percentage of the students who often dream during naps 
Table 2 Sleep-wake pattern in the groups with sleep problems

\begin{tabular}{|c|c|c|c|c|c|}
\hline & $\begin{array}{l}\text { Total } \\
(n=1034)\end{array}$ & $\begin{array}{l}\text { Insomnia } \\
(n=257)\end{array}$ & $\begin{array}{l}\text { BIISS } \\
(n=28)\end{array}$ & $\begin{array}{l}\text { DSWP } \\
(n=20)\end{array}$ & $\begin{array}{l}\text { BIISS + DSWP } \\
(n=46)\end{array}$ \\
\hline Sleep duration on weekdays (h) & $5.9 \pm 1.2$ & $5.7 \pm 1.3$ & $5.0 \pm 0.5$ & $6.8 \pm 0.9$ & $4.3 \pm 1.0$ \\
\hline Sleep duration on weekends ( $h$ ) & $8.0 \pm 1.5$ & $7.9 \pm 1.6$ & $8.5 \pm 1.6$ & $7.4 \pm 1.1$ & $8.6 \pm 1.8$ \\
\hline Bedtime on weekdays (h:m) & $0: 44 \pm 1: 07$ & $0: 57 \pm 1: 12$ & $0: 10 \pm 0: 22$ & $1: 34 \pm 0: 38$ & $2: 20 \pm 1: 01$ \\
\hline Bedtime on weekends (h:m) & $0: 55 \pm 1: 24$ & $1: 06 \pm 1: 28$ & $0: 39 \pm 2: 11$ & $1: 51 \pm 0: 46$ & $2: 31 \pm 1: 20$ \\
\hline Wake-up time on weekdays (h:m) & $6: 48 \pm 1: 03$ & $6: 44 \pm 1: 03$ & $5: 42 \pm 0: 42$ & $8: 31 \pm 0: 50$ & $6: 46 \pm 0: 54$ \\
\hline Wake-up time on weekends (h:m) & $9: 02 \pm 1: 48$ & $9: 11 \pm 1: 57$ & $9: 21 \pm 1: 41$ & $9: 32 \pm 0: 53$ & $11: 20 \pm 1: 43$ \\
\hline Extension of sleep duration on weekends (h) & $2.1 \pm 1.7$ & $2.3 \pm 2.0$ & $3.5 \pm 1.5$ & $0.7 \pm 0.6$ & $4.4 \pm 1.8$ \\
\hline MEQ score & $48.6 \pm 7.5$ & $47.9 \pm 7.7$ & $51.0 \pm 6.2$ & $37.1 \pm 2.8$ & $36.9 \pm 4.3$ \\
\hline \multicolumn{6}{|l|}{ Chronotype $^{a}$} \\
\hline Morning-type n (\%) & $95(9.2)$ & $22(8.6)$ & $4(14.3)$ & $0(0)$ & $0(0)$ \\
\hline Neutral-type n (\%) & $693(67.0)$ & $165(64.2)$ & $24(85.7)$ & $0(0)$ & $0(0)$ \\
\hline Evening-type n (\%) & $168(16.2)$ & $47(18.3)$ & $0(0)$ & $20(100)$ & $46(100)$ \\
\hline N/A n (\%) & $78(7.5)$ & $23(8.9)$ & - & - & - \\
\hline Athenes Insomnia Scale score & $6.2 \pm 3.7$ & $9.7 \pm 3.1$ & $7.5 \pm 3.7$ & $6.3 \pm 3.7$ & $8.4 \pm 3.6$ \\
\hline Athenes Insomnia Scale score $\geq 6$ n (\%) & $544(52.6)$ & $257(100)$ & $19(67.9)$ & $11(55.0)$ & $36(78.3)$ \\
\hline Insomniab n (\%) & $257(24.9)$ & $257(100)$ & $8(28.6)$ & $4(20.0)$ & $20(43.5)$ \\
\hline Epworth Sleepiness Scale score & $11.4 \pm 4.6$ & $12.4 \pm 4.4$ & $14.6 \pm 2.9$ & $11.0 \pm 4.0$ & $14.7 \pm 3.2$ \\
\hline Epworth Sleepiness Scale score $\geq 11$ n (\%) & $580(56.1)$ & $167(65.0)$ & $28(100)$ & $12(60.0)$ & $46(100)$ \\
\hline Sleep duration on weekdays < 6 h n (\%) & $395(38.2)$ & $119(46.3)$ & $28(100)$ & $0(0)$ & $46(100)$ \\
\hline Bed time after 1:00 am on weekdays $n(\%)$ & $534(51.6)$ & $153(59.5)$ & $0(0)$ & $20(100)$ & $46(100)$ \\
\hline
\end{tabular}

Values are expressed as mean \pm standard deviation for continuous variables

$N / A$ Unanswered

$M E Q$ Morningness-Eveningness questionnarie

${ }^{a}$ Chronotype: total score for the Morningness-Eveningness questionnaire score below 42 is defined as evening-type, 42-58 as neutral-type, and above 58 as morning-type

bInsomnia: Atenes Insomnia Scale score $\geq 6$ and one or more of "Difficulty in initiationg sleep", "Difficulty in maintaining sleep", and "Early morning awakening" BIISS Behaviorally induced insufficient sleep syndrome, DSWP Delayed sleep-wake phase

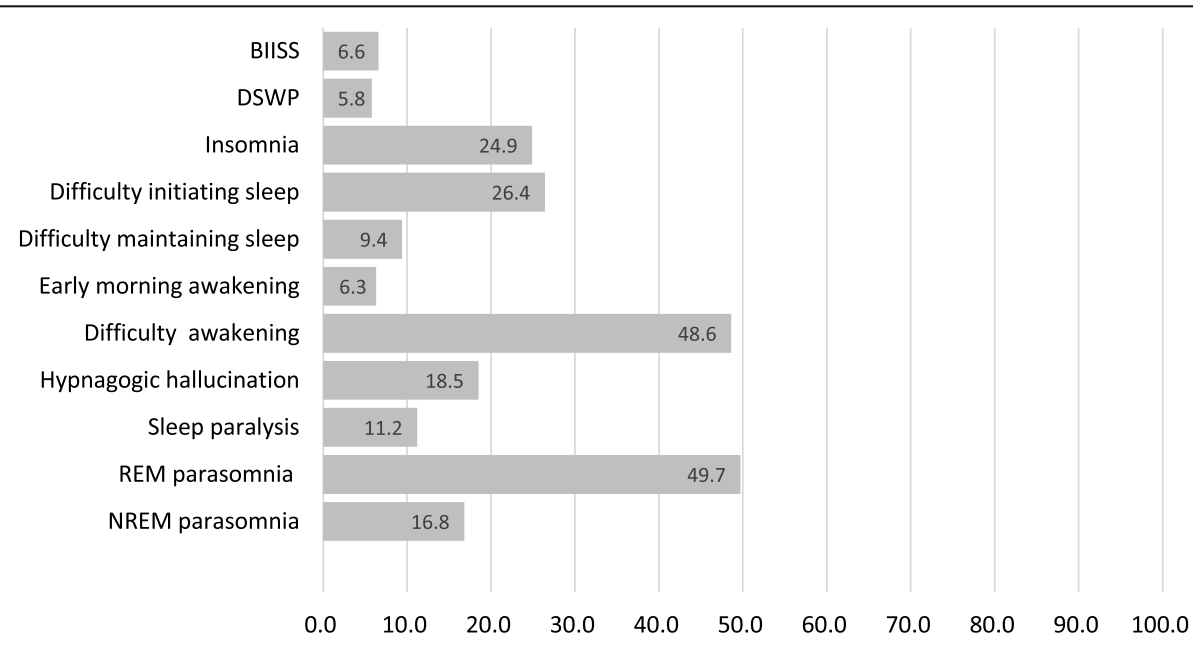

(\%)

Fig. 2 Prevalence of sleep problems and sleep-related symptoms. BIISS, behaviorally induced insufficient sleep syndrome: sleep duration on weekdays $<6 \mathrm{~h}$, difference in sleep duration on weekdays and weekends $\geq 2 \mathrm{~h}$, and Epworth Sleepiness Scale score $\geq 11$. DSWP, delayed sleepwake phase: bedtime before 1:00 am on weekdays and Morningness-Eveningness Questionnaire score < 42. Insomnia: Athens Insomnia Scale score $\geq 6$ and one or more of "Difficulty initiating sleep," "Difficulty maintaining sleep," and "Early morning awakening". REM parasomnia: nightmares and/or acting out dreams. NREM parasomnia: night terrors, defective awakening, and/or sleep walking 
Table 3 Sociodemographic and sleep characteristics and lifestyle in the groups with sleep problems

\begin{tabular}{|c|c|c|c|c|c|c|c|c|}
\hline & $\begin{array}{l}\text { Insomnia } \\
(n=257)\end{array}$ & $\begin{array}{l}\text { Without } \\
\text { Insomnia } \\
(n=754)\end{array}$ & $\begin{array}{l}\text { BIISS } \\
(n=28)\end{array}$ & $\begin{array}{l}\text { Without } \\
\text { BIISS } \\
(n=916)\end{array}$ & $\begin{array}{l}\text { DSWP } \\
(n=20)\end{array}$ & $\begin{array}{l}\text { Without } \\
\text { DSWP } \\
(n=936)\end{array}$ & $\begin{array}{l}\text { BIISS + } \\
\text { DSWP } \\
(n=46) \\
\end{array}$ & $\begin{array}{l}\text { Without BIISS } \\
+ \text { DSWP } \\
(n=898)\end{array}$ \\
\hline Age (y) & $19.8 \pm 1.2$ & $19.6 \pm 1.2^{a}$ & $20.0 \pm 1.2$ & $19.7 \pm 1.2$ & $19.8 \pm 1.0$ & $19.7 \pm 1.2$ & $19.9 \pm 1.0$ & $19.7 \pm 1.2$ \\
\hline \multicolumn{9}{|l|}{ Sex } \\
\hline Female (\%) & 79 & 78 & 100 & $79^{a}$ & 70 & 80 & 87 & 79 \\
\hline \multicolumn{9}{|l|}{ Grade } \\
\hline Freshman (\%) & 31 & 37 & 25 & 36 & 25 & 36 & 20 & 36 \\
\hline Sophomore (\%) & 24 & 23 & 25 & 23 & 15 & 23 & 28 & 22 \\
\hline Junior (\%) & 30 & 27 & 32 & 27 & 50 & 27 & 37 & 27 \\
\hline Senior (\%) & 16 & 14 & 18 & 15 & 10 & 15 & 15 & 15 \\
\hline \multicolumn{9}{|l|}{ Living alone } \\
\hline Yes (\%) & 21 & 21 & 0 & $22^{a}$ & 55 & $20^{a}$ & 17 & 21 \\
\hline Commute time (min) & $59.6 \pm 33.4$ & $59.5 \pm 34.4$ & $85.4 \pm 25.1$ & $58.5 \pm 33.5^{a}$ & $23.2 \pm 20.0$ & $60.0 \pm 33.3^{a}$ & $66.2 \pm 34.2$ & $58.9 \pm 33.5$ \\
\hline School hours (h) & $6.9 \pm 1.9$ & $7.0 \pm 1.8$ & $7.4 \pm 1.4$ & $7.0 \pm 1.8$ & $6.1 \pm 1.6$ & $7.0 \pm 1.8^{a}$ & $6.8 \pm 2.0$ & $7.0 \pm 1.8$ \\
\hline Class start time (h:m) & $9: 18 \pm 0: 46$ & $9: 20 \pm 0: 46$ & $8: 59 \pm 0: 26$ & $9: 18 \pm 0: 45^{a}$ & $\begin{array}{l}10: 04 \pm 1: \\
11\end{array}$ & $9: 17 \pm 0: 44^{a}$ & $9: 22 \pm 0: 51$ & $9: 18 \pm 1: 36$ \\
\hline Class closing time (h:m) & $\begin{array}{l}16: 11 \pm 1: \\
39\end{array}$ & $16: 17 \pm 1: 35$ & $\begin{array}{l}16: 22 \pm 1: \\
22\end{array}$ & $16: 15 \pm 1: 37$ & $\begin{array}{l}16: 07 \pm 1: \\
57\end{array}$ & $16: 15 \pm 1: 36$ & $16: 10 \pm 1: 39$ & $16: 16 \pm 1: 37$ \\
\hline
\end{tabular}

Club activities

$\begin{array}{lllllllll}\text { Yes (\%) } & 32 & 4^{a} & 14 & 31^{a} & 45 & 38 & 22 & 39^{a}\end{array}$

Part-time job

Yes (\%)

65

68

68

66

75

66

78

65

Exercise habit

$$
\text { Yes (\%) }
$$

46

49

25

$49^{a}$

50

47

33

$49^{a}$

Alcohol consumption

Yes (\%)

47

41

57

42

55

42

59

$42^{a}$

Smoking

Yes (\%)

6

5

4

5

20

$5^{a}$

4

5

Self-rated health status

Poor (\%)

41

$22^{a}$

25

27

20

27

39

26

Stress

Yes (\%)

56

$41^{a}$

46

45

45

45

65

$44^{a}$

Duration of nap

$<10 \mathrm{~min}(\%)$

27

31

10-29 min (\%)

30-59 min (\%)

$\geq 1 \mathrm{~h}(\%)$

21

$13^{b}$

31

30

20

30

$15 \quad 31$

Frequency of dreaming during nap

\section{Often (\%) \\ Sometimes (\%)}

Not (\%)

Sleep-related symptoms

Difficulty initiating sleep (\%) 76

Difficulty maintaining sleep (\%) 24

Early morning awakening (\%) 15

$\begin{array}{ll}18 & 12^{b} \\ 53 & 53 \\ 30 & 35\end{array}$

25

15

15

25
7
4

$\begin{array}{ll}26 & 30 \\ 10 & 5 \\ 6 & 0\end{array}$

26
10
6

22

$\begin{array}{ll}39 & 26^{a} \\ 13 & 9 \\ 4 & 6\end{array}$


Table 3 Sociodemographic and sleep characteristics and lifestyle in the groups with sleep problems (Continued)

\begin{tabular}{|c|c|c|c|c|c|c|c|c|}
\hline & $\begin{array}{l}\text { Insomnia } \\
(n=257)\end{array}$ & $\begin{array}{l}\text { Without } \\
\text { Insomnia } \\
(n=754)\end{array}$ & $\begin{array}{l}\text { BIISS } \\
(n=28)\end{array}$ & $\begin{array}{l}\text { Without } \\
\text { BIISS } \\
(n=916)\end{array}$ & $\begin{array}{l}\text { DSWP } \\
(n=20)\end{array}$ & $\begin{array}{l}\text { Without } \\
\text { DSWP } \\
(n=936)\end{array}$ & $\begin{array}{l}\text { BIISS + } \\
\text { DSWP } \\
(n=46) \\
\end{array}$ & $\begin{array}{l}\text { Without BIISS } \\
\text { + DSWP } \\
(n=898)\end{array}$ \\
\hline Difficulty awakening (\%) & 42 & $51^{a}$ & 43 & 49 & 80 & $49^{a}$ & 74 & $48^{a}$ \\
\hline $\begin{array}{l}\text { Hypnagogic hallucination } \\
(\%)\end{array}$ & 27 & $15^{a}$ & 32 & 18 & 15 & 19 & 35 & $18^{a}$ \\
\hline Sleep paralysis (\%) & 15 & $10^{a}$ & 11 & 12 & 15 & 11 & 20 & 11 \\
\hline REM parasomnia [7] (\%) & 57 & $47^{a}$ & 57 & 49 & 60 & 49 & 61 & 49 \\
\hline NREM parasomnia [8] (\%) & 24 & $15^{a}$ & 14 & 17 & 35 & $16^{a}$ & 24 & 16 \\
\hline
\end{tabular}

${ }^{a}$ significantly difference between the students with the sleep problem and without the sleep problem

${ }^{b}$ significantly higher than other students by residual analysis (adjusted residual $\geq 1.96$ )

BIISS Behaviorally induced insufficient sleep syndrome, DSWP Delayed sleep-wake phase

REM Rapid eye movement, NREM Non-rapid eye movement

REM parasomnia: nightmare and / or acting out their dreams

NREM parasomnia: night terrors, defective awakening, and / or sleep walking

was significantly higher than in groups without BIISS + DSWP. Regarding sleep-related symptoms, possible positivity for difficulty initiating sleep, difficulty awakening, and hypnagogic hallucination was more frequently observed in the BIISS + DSWP group than in those without BIISS + DSWP.

Factors associated with daytime dysfunction in school life The percentage of the students who reported "Often", "Sometimes", and "None" were 29 (3\%), 175 (17\%), and 822 (80\%) for absence; 40 (4\%), 256 (25\%), and 727 (70\%) for tardiness; and 175 (17\%), 666 (64\%), and 179 (17\%) for falling asleep during class, respectively. Further, 241 (23.3\%) students reported interference with academic achievement. Factors associated with daytime dysfunction in school life are shown in Table 4. Insomnia was associated with tardiness (aOR: 0.8 , 95\%CI: 0.70.9 ) and falling asleep during class (aOR: 1.6: 95\%CI: 1.4-2.0). BIISS was associated with tardiness (aOR: 1.5, 95\%CI: 1.1-2.2) and interference with academic achievement (aOR: 1.9, 95\%CI: 1.3-2.6). DSWP and BIISS + DSWP were associated with absence (aOR: 3.4, 95\%CI: 2.2-5.1 / aOR: 4.2, 95\%CI: 3.2-5.6), tardiness (aOR: 2.7, 95\%CI: 1.8-4.1 / aOR: 2.2, 95\%CI: 1.6-2.8), falling asleep during class (aOR: 2.6, 95\%CI: 1.4-4.8 / aOR: 7.6, 95\%CI: 3.3-17.2), and interference with academic achievement (aOR: 2.6, 95\%CI: 1.7-3.9 / aOR: 2.1, 95\%CI: $1.6-2.8)$.

\section{Discussion}

Insomnia, insufficient sleep and delayed sleep-wake phase in university students

The present study revealed the current statuses of university students with regard to insomnia, insufficient sleep, and delayed sleep-wake phase. In a previous systematic review on insomnia in university students, the prevalence of insomnia ranged from 9.4 to $38.2 \%$ [3537]. The prevalence of insomnia among the university students included in the present study fell within this range. In the present study, $24.9,2.7,1.9$, and $4.4 \%$ of students were categorized as having insomnia, BIISS (without DSWP), DSWP (without BIISS), and BIISS + DSWP, respectively. In contrast to the results of previous studies in which short sleep was judged only by the cut-off value of sleep duration (e.g., $<6 \mathrm{~h}$ ) [1, $4,8]$, we defined BIISS by including the following criteria; presence of daytime sleepiness and oversleeping on weekends. Likewise, DSWP was defined by assessing bedtime and MEQ score. Sleep duration and delayed sleep phase are correlated [38]; however, a number of previous studies that evaluated the impact of late chronotypes did not consider sleep duration $[3,39,40]$. Therefore, we defined BIISS, DSWP, and BIISS + DSWP more strictly by following the aforementioned criteria in order to investigate the actual impact of insufficient sleep and delayed sleep-wake phase. As a result, the prevalence of BIISS was less than $10 \%$ in the present study; however, about half of the total participants were suspected to have insufficient sleep because 38\% of them reported that their sleep duration was $<6 \mathrm{~h}$ on weekdays and half of them extended their sleep duration by $2 \mathrm{~h}$ on weekends and/or showed ESS score $\geq$ 11. Similarly, the actual prevalence of delayed sleepwake phase could also be higher than that reported in the present study (6\%) because $16 \%$ of the students were categorized as evening-type individuals. The sleep duration of students in our study was short; this is in line with the results of previous studies, which reported that the sleep duration of Japanese university students was shorter than those of university students in other countries [1]. In the present study, the prevalence of evening-type individuals $(16 \%)$ was lower than that of previous studies, which reported results that ranged from 20 to $35 \%$ [41-43]. 


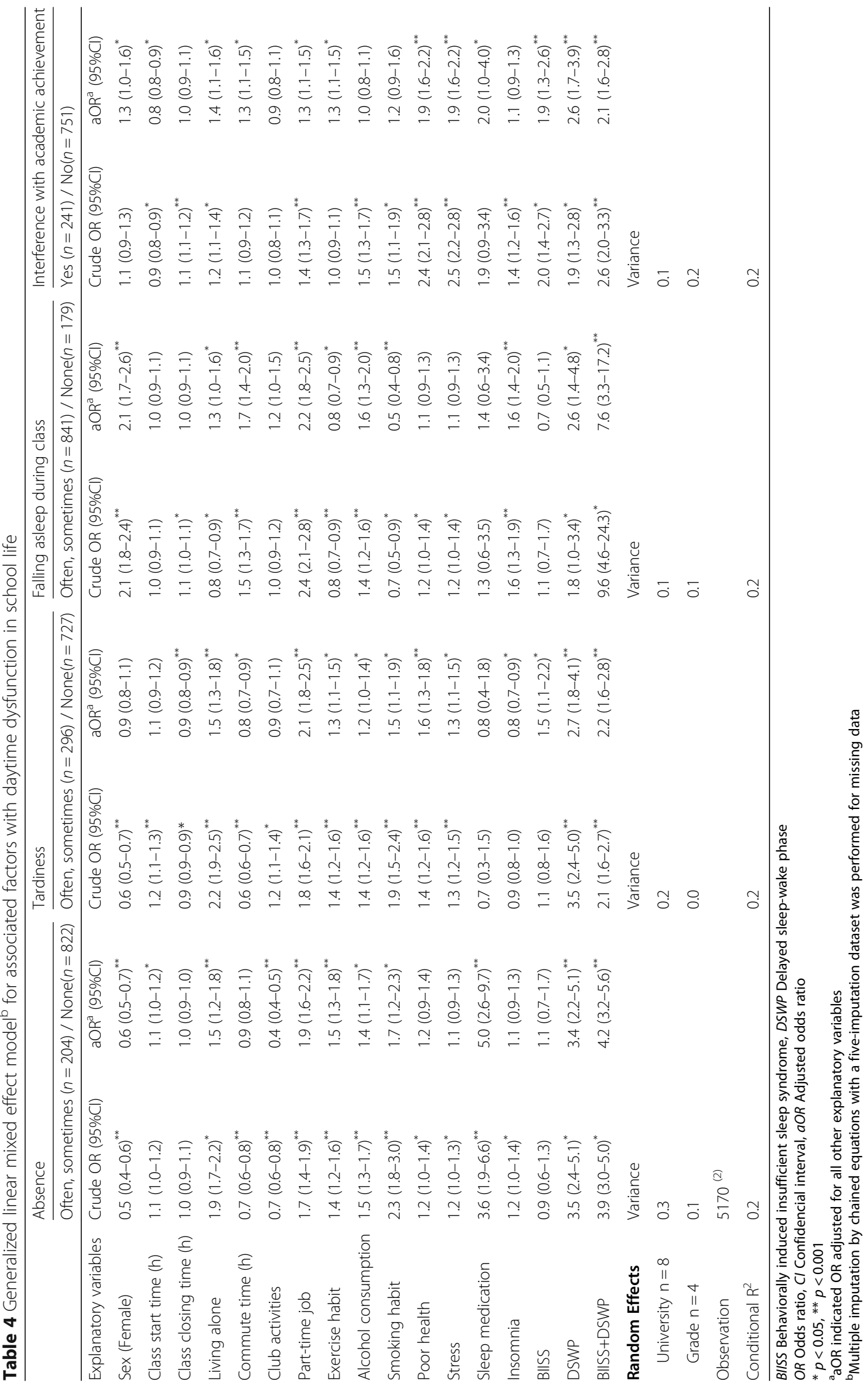




\section{Characteristics of each sleep problems}

The present study provided the characteristics of the aforementioned sleep problems considering not only participants' sociodemographic information or lifestyle but also their sleep-related symptoms. Although their sleep-related symptoms were not confirmed by face to face interview or validated screening scale, this is the first study to investigate these symptoms and their associations with sleep problems.

The prevalence of REM related symptoms such as hypnagogic hallucination and sleep paralysis were 19 and $11 \%$, respectively. In the general population, the prevalence of hypnagogic hallucination was $31 \%$ in the 15-44 age group and the symptom was associated with mental health disorders including anxiety disorders, depression disorders, and short sleep duration [44]. In contrast, the prevalence of sleep paralysis was $2 \%$ in the $15-$ 24 age group [45], and $13 \%$ in university students [46] and the symptom was also associated with mental/physical disease, non-restorative sleep, nocturnal leg cramps, and nightmares $[45,47]$. In the present study, the prevalence of NREM/REM parasomnia was 17 and 50\%, respectively. NREM/REM parasomnia are likely to be associated with insufficient sleep and a delayed sleep phase. In the case of REM parasomnia, nightmares are induced by stressful or traumatic events and are linked to insomnia [48]. Taking these results into account, these sleep-related symptoms may cause sleep problems or mental/physical dysfunction in the young adult population.

Hypnagogic hallucination (27\%), sleep paralysis (15\%), and REM/NREM parasomnia $(57 \% / 24 \%)$ other than insomnia symptoms (i.e., difficulty initiating sleep, difficulty maintaining sleep, early morning awakening) were more prevalent in the insomnia group than in the students without insomnia. This is consistent with the results of previous studies, which reported that hypnagogic hallucination was most frequent in individuals who had difficulty initiating sleep [49]. In the insomnia group, the percentage of the students who took a nap for over an hour was significantly higher than that in the students without insomnia. This may be as a result of unsatisfactory nocturnal sleep due to insomnia. Contrarily, taking a long nap during the day may disturb the sleep-wake rhythm and evoke hypnagogic hallucination. In a previous study, forced two-hour nap in the early evening shortened REM latency and worsened sleep efficiency following nocturnal sleep in young adults [50]. Generally, a short nap has a positive effect on daytime performance and reduces fatigue; therefore, appropriate timing and length of naps should be considered [51].

In the BIISS group, the prevalence of sleep-related symptoms did not differ from that recorded in the students without BIISS, despite the longer commute and earlier class start times. Interestingly, all students with BIISS were female who did not live alone. Thus, for these university students, it was suggested that insufficient sleep might be affected by external environmental factors.

Difficulty awakening (80\%) and NREM parasomnia (35\%) were more prevalent in the DSWP group than in the students without DSWP. The high prevalence of difficulty awakening in this group was reasonable because the students with DSWP needed to wake up earlier than their internal clock time. In contrast to the BIISS group, commute time was shorter and school start time later in the DSWP group than in the group without DSWP. Students with short commutes and late school start times were generally on time for school even though they wake up relatively later due to their age-dependent eveningness. Furthermore, it is possible that students with DSWP take late start classes as a coping strategy; that is, these two school lifestyles can be either cause DSWP or be an effect of it.

In the BIISS + DSWP group, difficulty initiating sleep (39\%), difficulty awakening (74\%), and hypnagogic hallucination (35\%) were more prevalent than in the students without BIISS + DSWP. In contrast to the students with only DSWP who could have a sufficient length of nocturnal sleep, the students with BIISS + DSWP would be forced to get up early. Moreover, their bedtime was quite late (2:20 $\pm 1: 01)$ and one fourth of them had difficulty initiating sleep. Given this, the BIISS + DSWP group included the students who have an evening-type chronotype due to their delayed internal clock but could wake up early in order to adjust to their social schedule. Therefore, students with BIISS + DSWP, most of whom are thought to be unaware of their delayed intrinsic circadian rhythm, may have profoundly worsened health in the long run.

\section{The association between sleep problems and daytime dysfunction in school life}

Delayed sleep-wake phase (DSWP and BIISS + DSWP) were associated with all instances of daytime school life dysfunction, i.e., absence, tardiness, falling asleep during class, and interference with academic achievement, whereas BIISS was associated with only tardiness and interference with academic achievement. Compared to DSWP, BIISS + DSWP showed higher aOR for absence and falling asleep during class. In students with BIISS + DSWP, most are thought to suffer from serious insufficient sleep as a result of being forced to get up early, despite their delayed internal clock. Thus, BIISS + DSWP is considered a relatively more serious condition compared to DSWP. Absence and tardiness may be caused by difficulty awakening in the morning. Absence is considered to be a more serious condition than 
tardiness, which was negatively associated with being female (aOR: 0.6). This finding is consistent with the previous report stating that men are more likely to show biological eveningness [2]. In this study, a quarter of the students internal clocks were considered delayed due to their difficulty in initiating sleep, many of whom may be unaware of their delay. Therefore, in order to prevent the acceleration of this phase delay, it is important that university students learn about age-dependent sleep problems i.e. delayed sleep-wake phase and resulting insufficient sleep, and to avoid staying up late and/or extending their sleep duration on weekends. In this present study, results showed that over $80 \%$ of the students had experienced falling asleep during class. Insomnia (aOR: 1.6), DSWP (aOR: 2.6) and BIISS + DSWP (aOR: 7.6) were all associated with falling asleep during class. The BIISS + DSWP group reported severe insufficient sleep i.e. $4.3 \mathrm{~h}$ on weekdays, and only $4.4 \mathrm{~h}$ on weekends, with a delayed sleep-wake phase i.e. 2:20 am weekday bedtime. Key aspects to improve university student daytime function are thus maintaining a regular sleep-wake cycle and extending sleep duration. Students who cannot improve daytime sleepiness and difficulty awakening even after these attempts should be examined for sleep disorders, such as circadian rhythm disorders, narcolepsy, sleep apnea syndrome, or restless legs syndrome. Association was confirmed between interference with academic achievement and BIISS (aOR: 1.9), DSWP (aOR: 2.6), and BIISS + DSWP (aOR: 2.1). This result coincided with the findings of previous studies that reported a similar association between sleep problems and worsened academic performance e.g. grade point or ranking $[8,9,12]$.

Some previous reports emphasized that delay of class start time improved academic outcomes in adolescents because of the consequent adjustment in their internal clocks $[52,53]$. In contrast, other studies reported that late class start times possibly lead to alcohol consumption and may have a negative influence on academic performance in university students [54]. Unlike adolescents (junior/senior high school students), university students can engage in activities such as alcohol consumption and working a part time job in the night, freely and without supervision. In this study, students who displayed alcohol consumption and smoking habits were more prevalent in the BIISS + DSWP and DSWP groups respectively. Although alcohol consumption and smoking are prohibited under the age of 20 by law in Japan, these students were not excluded from this study. Thus, the lower percentage of students in this study whom consume alcohol and smoke compared to other countries may thus be due to this law. Therefore, although we cannot conclude the association and causal relationship from this cross-sectional study without adjusting for confounding factors, a delayed sleep-wake phase might be influenced not only by students' internal clock, but also by their lifestyle habits. Further studies should clarify whether BIISS + DSWP is associated with alcohol consumption itself or with the drinking habits are necessary. Furthermore, having a part-time job was associated with absence, tardiness, falling asleep during class, and interference with academic achievement, independent of sleep problems. Further studies should investigate the reasons for which students engage in part-time work and the detailed schedules of students with part-time jobs.

In this study, sleep medication was associated with absence (aOR: 5.0) and interference with academic achievement (aOR: 2.0). It was unclear why participants took sleep medication. However, it can be assumed that students with worse physical/mental health status might be prescribed sleep medication at the hospital, as indicated by the associations between poor health and tardiness or interference with academic achievement, and between stress and interference with academic achievement. However, this cross-sectional study could not draw causal inferences due to the small number $(n=8)$ of students on sleep medication. A longitudinal study is thus needed in order to better understand the association between daytime dysfunction in school life and physical/mental health including sleep medication use.

\section{Study limitations}

This study had some limitations. First, differential diagnosis of sleep problems / sleep-related symptoms could not be done in this questionnaire-based study. Second, universities were not randomly selected, because survey data was collected from the universities where the research collaborators were able to directly contact the ethics committee. Therefore, our study sample may not be representative of Japanese university students and sampling bias might exist especially since the percentage of female students was high; this was because women's university and faculties (e.g., nursing) participated in this study. Eveningness is more severe in males [2]; therefore, the impact of sleep problem on school life may be stronger in male students. Third, the causal relationship between sleep problems and daytime function in school life could not be ascertained in this cross-sectional study. Further studies on prospective sleep evaluation using objective sleep parameters are needed. In addition, although the questionnaire inquired about sleep-related symptoms and daytime function in school life, due to the lack of a time-frame measurement, misleading associations could have been found. Fourth, sleep-related symptoms could not be diagnosed using the validated questionnaires. Finally, the potential impact of covariates that were not included in our analyses should be considered, because various social or lifestyle factors may influence both sleep problems and daytime dysfunction in school life. 


\section{Conclusions}

Students with DSWP and BIISS + DSWP were significantly associated with daytime dysfunction in school life, i.e. absence, tardiness, falling asleep during class and interference with academic achievement. Students displaying BIISS + DSWP were considered to have a relatively more serious condition compared with those with only insomnia, DSWP, or BIISS. It is therefore of utmost importance that university students aim to prevent DSWP and BIISS which were associated with daytime function in school life.

\section{Abbreviations \\ AIS: Athens Insomnia Scale; BIISS: Behaviorally induced insufficient sleep syndrome; DSWP: Delayed sleep-wake phase; ESS: Epworth Sleepiness Scale; MEQ: Morningness-Eveningness Questionnaire; NREM: Non-rapid-eye movement; REM: Rapid-eye movement; PSQI: Pittsburg Sleep Quality Index}

\section{Acknowledgements \\ The authors gratefully acknowledge all the university students who participated in the study and teaching staff at the universities who contributed to data collection. We would like to thank Editage (www. editage.com) for English language editing.}

\section{Authors' contributions}

MK designed the study, analysed data, and wrote the initial draft of the manuscript. TS assisted in the planning the survey, interpretation of data, and the preparation of the manuscript. TS and YI supervised the manuscript. $\mathrm{TM}, \mathrm{ME}, \mathrm{CK}$, and NK contributed to data collection. All other authors have contributed to interpretation and critically reviewed the manuscript. All authors approved the final version of the manuscript, and agree to be accountable for all aspects of the work in ensuring that questions related to the accuracy or integrity of any part of the work are appropriately investigated and resolved.

\section{Funding}

This work was supported by the Japan Society for the Promotion of Science [JP17K17534]. The funding bodies had no role in the design of the study, data collection, analysis and interpretation of data, and writing of the manuscript.

\section{Availability of data and materials}

The datasets used and/or analyzed during the current study are available from the corresponding author on reasonable request.

\section{Ethics approval and consent to participate}

Ethical approval for this survey was granted by the Ethical Committee of the Tokyo Medical University and Institute of Neuropsychiatry. All participants completed a written informed consent.

\section{Consent for publication}

Not applicable.

\section{Competing interests}

Department of Somnology is an endowment department, supported with an unrestricted grant from Philips Japan Co., Ltd. and Koike Medical Co., Ltd.

\footnotetext{
Author details

${ }^{1}$ Department of Somnology, Tokyo Medical University, 6-7-1 Nishishinjuku, Shinjuku-ku, Tokyo 160-0023, Japan. 2Japan Somnology Center, Institute of Neuropsychiatry, 5-10-10, Yoyogi, Shibuya-ku, Tokyo 151-0053, Japan. ${ }^{3}$ Department of Nursing, Graduate School of Medicine, Yokohama City University, Fukuura 3-9, Yokohama, Kanazawa-ku, Kanagawa 236-0004, Japan. ${ }^{4}$ Department of Medical Technology, School of Health Sciences, Tokyo University of Technology, Nishikamata 5-23-22, Ota-ku, Tokyo 144-0051, Japan. ${ }^{5}$ Child Development and Education, Faculty of Humanities, Wayo Women's University, Konodai 2-3-1, Ichikawa, Chiba 272-0827, Japan. ${ }^{6}$ Department of Nursing, Faculty of Medical Sciences, Shonan University of
}

Medical Sciences, Kamishinano 16-48, Yokohama, Totsuka-ku, Kanagawa 244-0806, Japan. 7 Department of Clinical Laboratory Science, Faculty of Medical Technology, Teikyo University, Kaga 2-11-1, Itabashi-ku, Tokyo 173-8605, Japan.

Received: 31 October 2019 Accepted: 9 March 2020

Published online: 20 March 2020

\section{References}

1. Steptoe A, Peacey V, Wardle J. Sleep duration and health in young adults. Arch Intern Med. 2006;166(16):1689-92.

2. Roenneberg T, Kuehnle T, Pramstaller PP, Ricken J, Havel M, Guth A, et al. A marker for the end of adolescence. Curr Biol. 2004;14(24):R1038-9.

3. Haraden DA, Mullin BC, Hankin BL. The relationship between depression and chronotype: a longitudinal assessment during childhood and adolescence. Depress Anxiety. 2017;34(10):967-76.

4. Kristicevic T, Stefan L, Sporis G. The associations between sleep duration and sleep quality with body-mass index in a large sample of young adults. Int J Environ Res Public Health. 2018;15(4):E758.

5. Supartini A, Honda T, Basri NA, Haeuchi Y, Chen S, Ichimiya A, et al. The impact of sleep timing, sleep duration, and sleep quality on depressive symptoms and suicidal ideation amongst Japanese freshmen: the EQUSITE study. Sleep Disorders. 2016;2016:8737654

6. Morita Y, Sasai-Sakuma T, Asaoka S, Inoue Y. Prevalence and correlates of insufficient sleep syndrome in Japanese young adults: a web-based crosssectional study. J Clin Sleep Med. 2015;11(10):1163-9.

7. Suh S, Yang HC, Kim N, Yu JH, Choi S, Yun CH, et al. Chronotype differences in health behaviors and health-related quality of life: a population-based study among aged and older adults. Behav Sleep Med. 2017;15(5):361-76.

8. Kelly WEK, K E, Clanton C. The relationship between sleep length and grade-point average among college students. Coll Stud J. 2001;35(1):84.

9. Lee YJ, Park J, Kim S, Cho SJ, Kim SJ. Academic performance among adolescents with behaviorally induced insufficient sleep syndrome. J Clin Sleep Med. 2015;11(1):61-8.

10. Stroebele N, McNally J, Plog A, Siegfried S, Hill JO. The association of selfreported sleep, weight status, and academic performance in fifth-grade students. J Sch Health. 2013;83(2):77-84.

11. Tonetti $L$, Natale $V$, Randler C. Association between circadian preference and academic achievement: a systematic review and meta-analysis. Chronobiol Int. 2015;32(6):792-801.

12. Zerbini G, van der Vinne V, Otto LKM, Kantermann T, Krijnen WP, Roenneberg $T$, et al. Lower school performance in late chronotypes: underlying factors and mechanisms. Sci Rep. 2017;7(1):4385.

13. Ahrberg K, Dresler M, Niedermaier S, Steiger A, Genzel L. The interaction between sleep quality and academic performance. J Psychiatr Res. 2012; 46(12):1618-22.

14. Fatima Y, Doi SA, Najman JM, Mamun AA. Exploring gender difference in sleep quality of young adults: findings from a large population study. Clin Med Res. 2016;14(3-4):138-44.

15. Kabrita CS, Hajjar-Muca TA. Sex-specific sleep patterns among university students in Lebanon: impact on depression and academic performance. Nat Sci Sleep. 2016;8:189-96.

16. Pensuksan WC, Lertmaharit S, Lohsoonthorn V, Rattananupong $T$, Sonkprasert T, Gelaye B, et al. Relationship between poor sleep quality and psychological problems among undergraduate students in the southern Thailand. Walailak J Sci Technol. 2016;13(4):235-42.

17. Bhandari PM, Neupane D, Rijal S, Thapa K, Mishra SR, Poudyal AK. Sleep quality, internet addiction and depressive symptoms among undergraduate students in Nepal. BMC Psychiatry. 2017;17(1):106.

18. Seun-Fadipe CT, Mosaku KS. Sleep quality and psychological distress among undergraduate students of a Nigerian university. Sleep Health. 2017;3(3):190-4

19. Ghrouz AK, Noohu MM, Dilshad Manzar M, Warren Spence D, BaHammam AS, Pandi-Perumal SR. Physical activity and sleep quality in relation to mental health among college students. Sleep Breathing = Schlaf \& Atmung. 2019;23(2):627-34

20. Buysse DJ, Reynolds CF 3rd, Monk TH, Berman SR, Kupfer DJ. The Pittsburgh sleep quality index: a new instrument for psychiatric practice and research. Psychiatry Res. 1989;28(2):193-213.

21. Adolecent sleep working group Coa, and Council on school health. School start times for adolescents. Pediatrics. 2014;134(3):642-9. 
22. Chan NY, Zhang J, Yu MW, Lam SP, Li SX, Kong AP, et al. Impact of a modest delay in school start time in Hong Kong school adolescents. Sleep Med. 2017;30:164-70.

23. Owens JA, Belon K, Moss P. Impact of delaying school start time on adolescent sleep, mood, and behavior. Arch Pediatr Adolesc Med. 2010;164(7):608-14.

24. Owens JA, Dearth-Wesley T, Herman AN, Oakes JM, Whitaker RC. A quasiexperimental study of the impact of school start time changes on adolescent sleep. Sleep Health. 2017;3(6):437-43.

25. Johns MW. A new method for measuring daytime sleepiness: the Epworth sleepiness scale. Sleep. 1991;14(6):540-5.

26. Takegami M, Suzukamo Y, Wakita T, Noguchi H, Chin K, Kadotani H, et al. Development of a Japanese version of the Epworth sleepiness scale (JESS) based on item response theory. Sleep Med. 2009;10(5):556-65.

27. Horne JA, Ostberg O. A self-assessment questionnaire to determine morningness-eveningness in human circadian rhythms. Int J Chronobiol. 1976;4(2):97-110.

28. Ishihara K, Miyashita A, Inugami M, Fukuda K, Yamazaki K, Miyata Y. The results of investigation by the Japanese version of MorningnessEveningness questionnaire. Shinrigaku Kenkyu. 1986;57(2):87-91.

29. Soldatos CR, Dikeos DG, Paparrigopoulos TJ. Athens insomnia scale: validation of an instrument based on ICD-10 criteria. J Psychosom Res. 2000; 48(6):555-60.

30. Okajima I, Nakajima S, Kobayashi M, Inoue Y. Development and validation of the Japanese version of the Athens insomnia scale. Psychiatry Clin Neurosci. 2013;67(6):420-5.

31. Van Buuren S, Groothuis-Oudshoorn K. Mice: multivariate imputation by chained equations in R. J Stat Softw. $2011 ; 45(3)$ https://www.jstatsoft.org/ article/view/v045i03/v45i03.pdf.

32. Bates D, Maechler M, Bolker B, Walker S, Christensen R, Singmann $H$, et al. Linear mixed-effects models using 'Eigen' and S4; 2019. [Available from: https://github.com/Ime4/Ime4/.

33. Buuren S, Groothuis-Oudshoorn K, Robitzsch A, Vink G, Doove L, Jolani S, et al. Multivariate imputation by chained equations; 2019. [Available from: https://github.com/stefvanbuuren/mice.

34. von Elm E, Altman DG, Egger M, Pocock SJ, Gotzsche PC, Vandenbroucke $J P$, et al. The strengthening the reporting of observational studies in epidemiology (STROBE) statement: guidelines for reporting observational studies. J Clin Epidemiol. 2008;61(4):344-9.

35. Jiang $X L$, Zheng $X Y$, Yang J, Ye CP, Chen $Y Y$, Zhang ZG, et al. A systematic review of studies on the prevalence of insomnia in university students. Public Health. 2015;129(12):1579-84.

36. Sivertsen B, Vedaa O, Harvey AG, Glozier N, Pallesen S, Aaro LE, et al. Sleep patterns and insomnia in young adults: a national survey of Norwegian university students. J Sleep Res. 2019;28(2):e12790.

37. Choueiry N, Salamoun T, Jabbour H, El Osta N, Hajj A, Rabbaa KL. Insomnia and relationship with anxiety in university students: a cross-sectional designed study. PLoS One. 2016;11(2):e0149643.

38. Roenneberg T, Kuehnle T, Juda M, Kantermann T, Allebrandt K, Gordijn M, et al. Epidemiology of the human circadian clock. Sleep Med Rev. 2007;11(6):429-38.

39. Haregu A, Gelaye B, Pensuksan WC, Lohsoonthorn V, Lertmaharit S, Rattananupong T, et al. Circadian rhythm characteristics, poor sleep quality, daytime sleepiness and common psychiatric disorders among Thai college students. Asia-Pacific Psychiatry. 2015;7(2):182-9.

40. Rose D, Gelaye B, Sanchez S, Castaneda B, Sanchez E, Yanez ND, et al. Morningness/eveningness chronotype, poor sleep quality, and daytime sleepiness in relation to common mental disorders among Peruvian college students. Psychol Health Med. 2015;20(3):345-52.

41. Rique $G L$, Fernandes Filho GM, Ferreira AD, de Sousa-Munoz RL. Relationship between chronotype and quality of sleep in medical students at the Federal University of Paraiba, Brazil. Sleep Sci. 2014;7(2):96-102.

42. Kabrita CS, Hajjar-Muca TA, Duffy JF. Predictors of poor sleep quality among Lebanese university students: association between evening typology, lifestyle behaviors, and sleep habits. Nat Sci Sleep. 2014;6:11-8.

43. Schlarb AA, Classen M, Grunwald J, Vogele C. Sleep disturbances and mental strain in university students: results from an online survey in Luxembourg and Germany. Int J Ment Heal Syst. 2017;11:24.

44. Ohayon MM. Prevalence of hallucinations and their pathological associations in the general population. Psychiatry Res. 2000;97(2-3):153-64

45. Ohayon MM, Zulley J, Guilleminault C, Smirne S. Prevalence and pathologic associations of sleep paralysis in the general population. Neurology. 1999; 52(6):1194-200.
46. O'Hanlon J, Murphy M, Di Blasi Z. Experiences of sleep paralysis in a sample of Irish university students. Ir J Med Sci. 2011;180(4):917-9.

47. Liskova M, Janeckova D, Kluzova Kracmarova L, Mlada K, Buskova J. The occurrence and predictive factors of sleep paralysis in university students. Neuropsychiatr Dis Treat. 2016;12:2957-62.

48. Singh S, Kaur H, Singh S, Khawaja I. Parasomnias: a comprehensive review. Cureus. 2018;10(12):e3807.

49. Ohayon MM, Sagales T. Prevalence of insomnia and sleep characteristics in the general population of Spain. Sleep Med. 2010;11(10):1010-8.

50. Werth E, Dijk DJ, Achermann P, Borbely AA. Dynamics of the sleep EEG after an early evening nap: experimental data and simulations. Am J Physiol. 1996;271(3 Pt 2):R501-10.

51. Milner CE, Cote KA. Benefits of napping in healthy adults: impact of nap length, time of day, age, and experience with napping. J Sleep Res. 2009; 18(2):272-81.

52. Wheaton AG, Chapman DP, Croft JB. School start times, sleep, behavioral, health, and academic outcomes: a review of the literature. J Sch Health. 2016;86(5):363-81.

53. Thacher PV, Onyper SV. Longitudinal outcomes of start time delay on sleep, behavior, and achievement in high school. Sleep. 2016;39(2):271-81.

54. Onyper SV, Thacher PV, Gilbert JW, Gradess SG. Class start times, sleep, and academic performance in college: a path analysis. Chronobiol Int. 2012; 29(3):318-35.

\section{Publisher's Note}

Springer Nature remains neutral with regard to jurisdictional claims in published maps and institutional affiliations.
Ready to submit your research? Choose BMC and benefit from:

- fast, convenient online submission

- thorough peer review by experienced researchers in your field

- rapid publication on acceptance

- support for research data, including large and complex data types

- gold Open Access which fosters wider collaboration and increased citations

- maximum visibility for your research: over $100 \mathrm{M}$ website views per year

At BMC, research is always in progress.

Learn more biomedcentral.com/submissions 